\title{
Quiz-o-Matic: A free Web-based tool for construction of self-scoring on-line quizzes
}

\author{
REBECCA J. WHITE and COREY A. HAMMER \\ DePaul University, Chicago, Illinois
}

\begin{abstract}
Increasingly, educators are using the World-Wide Web (the Web) and related technology to supplement their traditional teaching materials. In this paper, we present a free tool that has been placed on the Web to enable educators to create Web pages that present self-scoring quizzes. Such Web-based practice quizzes provide students with an opportunity for interactive assessment and review of course material. The tool, Quiz-o-Matic, uses active server pages to build the HTML and JavaScript code for each quiz, without requiring the user to edit any code. We present evidence that students judge the selfscoring quizzes to be useful and worthwhile additions to a course.
\end{abstract}

The World-Wide Web (the Web) has revolutionized information exchange on many levels, including the manner in which educators are able to teach. In fact, educators are increasingly using Web technology to augment traditional teaching materials and methodology. The 1999 National Survey of Information Technology in Higher Education by the Campus Computing Project has estimated that the percentage of college courses using Web resources in syllabi rose to $38.9 \%$ in 1999 from $33.1 \%$ in 1998 . This survey of 557 public and private higher education institutions across the United States indicates that more than one fourth $(28.1 \%)$ of all college courses currently offer a course Web page, up from $22.5 \%$ in 1998 . In addition, the 1999 Campus Computing Survey data reveal that about one-fifth (19\%) of college faculty members maintain a personal Web page.

Although educators are increasingly incorporating the Internet into their teaching, there can be some challenges when one attempts to do so. The Campus Computing Project found that the ability of faculty to "integrate information technology into instruction" remained the single most challenging issue facing information technology (IT) in higher education. Many educators claim that the benefits of using technology are worth the effort needed to learn and implement these tools, but these possible effects may not always outweigh potentially high costs of time and effort in using technology (Murray, 1999). Given that Internet technology can support learning, an important objective should be to facilitate the educator's ability to use it more easily.

The authors thank Philip Horvath and the DePaul Academic Technology Development office for their technical support and hosting of the Quiz-o-Matic. We also thank Ching-Fan Sheu for discussions concerning this project and Joseph Ferrari for supporting the use of the practice quiz template in his course, as well as for allowing data to be collected. Correspondence may be addressed to R. White, Department of Psychology, DePaul University, 2219 N. Kenmore Ave., Chicago, IL 60614 (e-mail: rwhite1@,condor.depaul.edu).
Internet technology has the potential to involve students in course material and discussions outside of the classroom. Computer-based teaching methods can enhance the transfer of information and increase student motivation (Forsyth \& Archer, 1997), as well as improve student performance (Worthington, Welsh, Archer, Mindes, \& Forsyth, 1996). Many references are available that describe the types of support materials that one can offer on the Web, as well as the technology that is necessary to implement their use (Brooks, 1997; Khan, 1997). Use of the Internet to provide course supplements is not limited to presenting static information such as course syllabi. Dynamic applications, such as on-line discussion groups, concept demonstrations, and interactive methods of feedback (e.g., practice quizzes), can also be offered.

Practice quizzes can be a useful means of helping students learn information presented in a course and can allow students to assess their knowledge of course material. Paper and pencil practice tests have been shown to increase students' performance on aptitude and achievement tests (Kulik, Kulik, \& Bangert, 1984). In addition, it has been demonstrated that after using a computerized practice test, previously low-performing students improved their exam performance (Lee-Sammons \& Wollen, 1989). The benefits of offering practice quizzes on the Web include novel presentation of course materials and accessibility to quizzes outside of the classroom. On-line practice quizzes also offer immediate feedback to students. Interactive study materials such as these may promote selfregulated learning (Brooks, 1997).

One can construct a Web-based practice quiz that provides students with immediate feedback by using a number of different Internet-related programming and scripting languages, including JavaScript and active server pages (ASP). A free on-line quiz-generating application created by the authors, Quiz-o-Matic, eliminates the need for instructors to edit any JavaScript, ASP, or hypertext markup language (HTML) code. The Quiz-o-Matic application also does not require any common gateway interface 


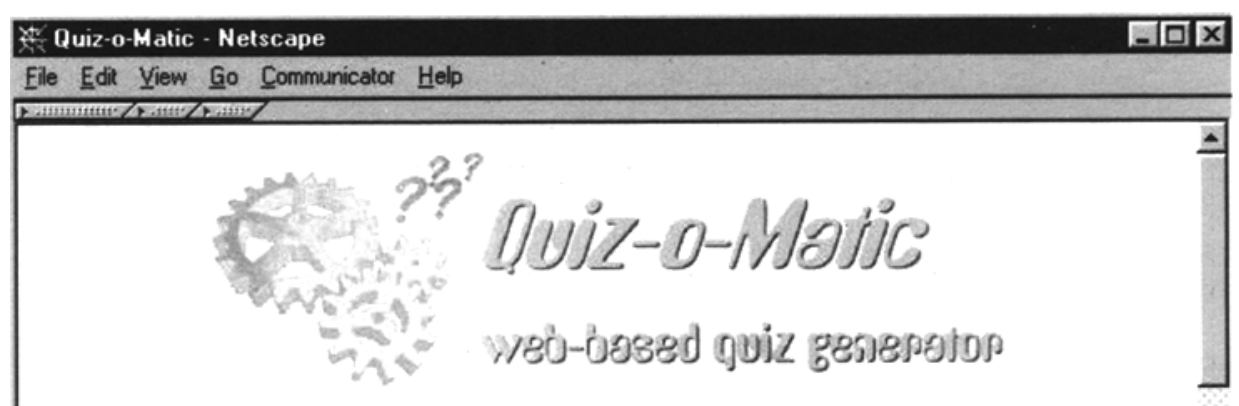

Welcome to Quiz-o-Matic, a Web-based Practice Quiz Generator

Now, enter the title, directions, questions, answers, and home page URL for your quiz. For each question, you may submit up to 5 possible answers. Leave any extra answer fields blank. Click on the radio button that corresponds with the correct answer for each question.

Title:

Psychology Practice Quiz \#1

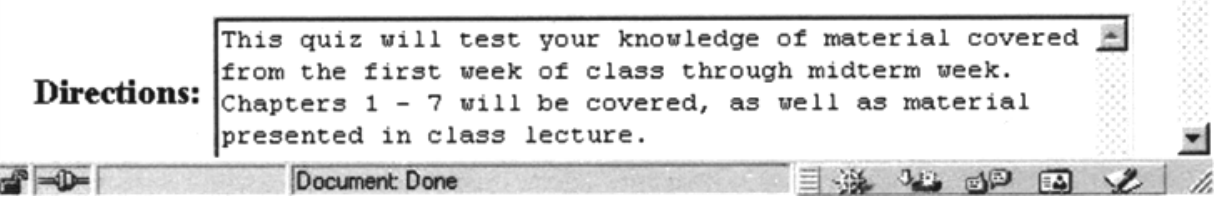

Figure 1. Entering the title and directions for a quiz in Quiz-o-Matic.

(CGI) or server-side programs to implement the practice quizzes, which makes their use relatively easy. Knowledge of HTML, JavaScript, or ASP is not necessary to use the quiz-building application that is presented in this paper. However, it is assumed that the reader has knowledge of how to publish a Web document on the Internet, or has access to a technical or Web development support person who can publish the document on line.

\section{Use of the Quiz-o-Matic Tool}

The Quiz-o-Matic can be accessed from the project Web site at http://www.depaul.edu/ rwhitel/quiz. The Quiz-o-Matic application easily generates a Web page that contains a self-scoring quiz for the user. The finished document presents students with questions and allows them to select their answers by clicking on the appropriate radio button for their choice. When the user clicks on a button labeled "grade my quiz," he/she receives immediate feedback on the percent correct, as well as on the specific correct and incorrect answers.

The Quiz-o-Matic application embeds submitted questions and answers into JavaScript and HTML code, creating a Web page that the educator can save as a file and post on a Web site. The generated practice quiz can have a multiple-choice and/or true-false format and allows the user to create a quiz that contains from 2 to 99 questions, with up to five possible answers each. After specifying the number of questions, the user inputs the title, directions, and question items (see Figure 1) for the quiz. As seen in Figure 2, the user enters the quiz answers, leaving any extra answer fields blank, and then selects the radio button that corresponds to the correct answer to the question. When the user is finished entering all relevant information into the application, the quiz can be submitted by clicking the "Build my Quiz" button, which takes the user to the completed practice quiz. It is important that the user save the completed quiz on this Web page as a file in a home directory, or it will be lost. The Quiz-o-Matic application does not host quizzes for the user. Rather, it generates the quiz and displays it. The author must save the finished quiz as an HTML document on a local drive and publish the file on line. To save the file, the user can go to "File" and then "Save As..." in the Web browser toolbar, saving the file with an ".htm" or ".html" extension. Alternatively, if this method of saving the finished Web document does not work on the user's browser, the user can click on "View" followed by "Page Source." This will display the code for the generated Web page, which can then be highlighted and copied (using control-C on the keyboard), and then pasted (using control-V on the keyboard) into a text editor. This file can then be saved from the text editor as an HTML file. After having saved the file, the author of the quiz can publish the file just as any other Web document. Detailed instructions for each step of the quiz-creation process are available at the Web site.

\section{Use of Web Practice Quizzes in Introductory Psychology}

The Quiz-o-Matic was used to construct practice quizzes during two terms of an introductory psychology course. For each term, three optional practice quizzes 


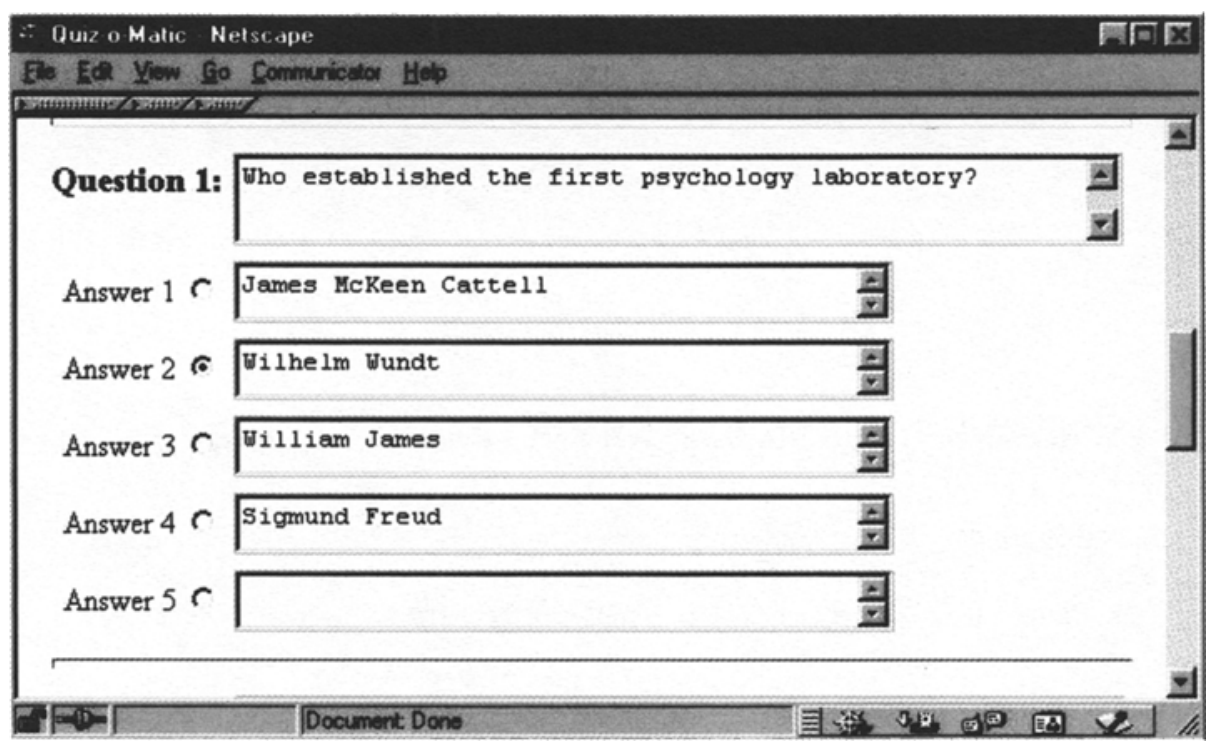

Figure 2. Entering a question with four possible answer choices and selecting the correct answer.

were offered through the course Web site, one practice quiz corresponding with each exam in the class. The quiz material came from chapters to be covered in the exam. At the end of each term, a survey was distributed to all of the students present at a regular class meeting. The survey used a 7-point Likert scale format $(1=$ negative response; 7 = positive response $)$. In total, 161 students $(107 \mathrm{fe}-$ males, 51 males) were surveyed regarding their use of the practice quizzes offered in class (White \& Hammer, 1999).

The majority of students $(56.5 \%, n=91)$ used the optional practice quizzes offered on the course Web page at least once. Overall, students reported their comfort level in using the Internet as generally high $(M=5.74, S D=$ 1.47).

The students who used the practice quizzes evaluated their use of these quizzes very favorably. They rated them as generally useful $(M=5.65, S D=1.04)$ and specifically useful for studying $(M=5.58, S D=.91)$. These students also rated the quiz as fairly easy to use $(M=5.89, S D=$ 1.21 ). When the students who used the quizzes were asked if they would use a similar quiz if it were offered in other courses, most reported that they "definitely would" $(M=6.32, S D=.91)$.

Students who did not use the practice quizzes $(43.5 \%$, $n=70$ ) were asked to endorse possible reasons for why they did not use the quizzes. The most frequently cited reason by this group was lack of time to access them $(50 \%, n=35)$, followed by lack of easy access to the Internet $(25.7 \%, n=18)$. The students who did not use the practice quizzes also often reported that they didn't know where to find the quizzes $(24.3 \%, n=17)$, that they didn't need the practice $(21.4 \%, n=15)$, and that they didn't like taking practice quizzes $(18.6 \%, n=13)$. Interestingly, the most infrequently endorsed reason offered by students who did not use the quizzes was that they were not familiar with the Internet $(7.1 \%, n=5)$. The use of this quiz was completely optional for students, so these data may be helpful in the attempt to assess how students might be encouraged and motivated to use materials available on the Web.

Although an evaluation of the effects on test performance and other outcomes has yet to be completed, the data are encouraging for anyone who wishes to use practice quizzes and other on-line materials in teaching. The majority of students in these classes used the practice quizzes, reported that they felt that the quizzes were helpful, and reported that they were highly likely to use a similar quiz in the future, if offered.

\section{JavaScript and Active Server Pages}

Although the Quiz-o-Matic tool makes editing JavaScript and ASP code unnecessary, JavaScript and ASP are useful tools that can be used to create other interactive Web documents. JavaScript is a scripting language originally derived from Netscape's LiveScript; it was developed by Sun Microsystems and Netscape. JavaScript is embedded within an HTML document, allowing one to add dynamic and interactive features to Web pages, such as calculations, form verification, and many other responses to actions of the user. Because JavaScript is used here as a client-side scripting language, the user's computer executes all of the processing. The result is a decrease in problems posed by server-side applications, such as security risks, bandwidth requirements, and server load. JavaScript does not rely on a server for delivery in the manner that Java programs, known as applets, do. This means that the scripts, embedded in the HTML file, load immediately with the Web document. Further information may be obtained from JavaScript reference books (Flanagan, 1988; Kent \& Multer, 1997). 
JavaScript applications require a JavaScript-enabled browser. The current version of JavaScript, 1.2, is supported by Netscape Navigator $4.0+$ and Microsoft Internet Explorer 4.0+ (Kent \& Multer, 1997). In the past, there has been a lack of standardization and support of JavaScript between these two most widely used browsers. However, Netscape and Internet Explorer now support most JavaScript elements, including those used in the practice quizzes described here.

The Quiz-o-Matic application was constructed with ASP. ASP has become a standard for developing serverside Web applications, or applications that occur on the server housing the script rather than on the user's computer. ASP code is interpreted and converted to HTML on the server; the results are then sent back to the browser and are displayed. Thus, ASP allows Web developers to dynamically generate browser content, as well as allows access to databases, updating of content, and customization. In order to use ASP, one would ideally be running a Windows NT Server with Internet Information Server Version 3.0, or higher. ASP also can run on Windows NT Workstation 4.0 and Windows 95 , or higher versions with Windows Option Pack 4.0. The Windows NT Server 4.0 Option Pack from Microsoft, including the Internet Information Server Version 4.0, can be downloaded free from the Microsoft Web site at http://www.microsoft.com/ ntserver/nts/downloads/recommended/NT4OptPk/ default.asp.

Several UNIX and other non-Microsoft environments can also run ASP, but these require a third party tool in order to translate the ASP before it is sent to the client. Companies such as Chili!Soft and Halcyon Software offer products of this nature. To run ASP from a supporting server, one need only create the ASP files on the server with a ".asp" extension. When the browser requests the file, the server will preprocess the file before sending it. ASP technology was developed to be compatible with Microsoft products such as Internet Explorer. However, virtually all browsers, including Netscape Navigator, support ASP technology. ASP is a flexible technology that is able to be used in conjunction with Visual Basic Script (VBScript), Java, and JavaScript, making it useful in many contexts. For more information on using ASP technology, many reference books are available (Powers \& Petrusha, 1999; Weissinger, 1999).

\section{DISCUSSION}

There are many benefits to using Internet technology to supplement the materials presented in a course. The ability to use interactive and novel methods of presenting information and to encourage students to use course material outside of the classroom are a few of these benefits. Educators are encouraged to further learn how they might use Web technology to supplement their traditional teaching materials by referring to some of the many reference materials available (Brooks, 1997; Flanagan,
1988; Holzschlag, 1999; Kent \& Multer, 1997; Khan, 1997).

The use of an on-line practice quiz is an example of the type of interactive component that can be used on a course Web site. The Quiz-o-Matic was designed with the goal of making the creation of interactive applications simple, even for those who have little Web scripting experience. However, those who are familiar with JavaScript and HTML will also find the tool to be useful. Creating a practice quiz using Quiz-o-Matic takes much less time than scripting the same Web page by hand. Those who have knowledge of JavaScript and HTML are encouraged to use the tool as an example of other types of Web-based tools that can be made available. The creation of similar types of tools would simplify the use of interactive Webbased applications for educators. Currently, some similar types of Web exercise builders are available on line. Examples of additional on-line teaching supplements will be updated at the Quiz-o-Matic project Web site located at http://www.depaul.edu/ rwhite1/quiz/res.html.

\section{REFERENCES}

Brooks, D. W. (1997). Web-Teaching: A guide to designing interactive teaching for the World-Wide Web. New York: Plenum.

Flanagan, D. (1988). Javascript: The definitive guide (3rd ed.). Sebastopol, CA: O'Reilly \& Associates.

Forsyth, D. R., \& ARChER, C. R. (1997). Technologically assisted instruction and student mastery, motivation, and matriculation. Teaching of Psychology, 24, 207-212.

HolzschlaG, M. E. (1999). Special edition using HTML 4 (5th ed.). Indianapolis, IN: Que.

KeNT, P., \& MulTER, K. (1997). Official Netscape JavaScript 1.2 programmer's reference. Research Triangle Park Group, NC: Ventana Communications Group.

KHAN, B. H. (ED.) (1997). Web-based instruction. Englewood Cliffs, NJ: Educational Technology Publications.

KuliK, J. A., KuliK, C. C., \& BANGERT, R. L. (1984). Effects of practice on aptitude and achievement test scores. American Educational Research Journal, 21, 435-447.

LeE-Sammons, W. H., \& Wollen, K. A. (1989). Computerized practice tests and effects on in-class exams. Behavior Research Methods, Instruments, \& Computers, 21, 189-194.

MurRay, B. (1999, April). Technology invigorates teaching, but is the pazzazz worth the price? APA Monitor. Retrieved July 15, 1999 at http://www.apa.org/monitor/apr99/faculty.html

Powers, S., \& Petrusha R. (1999). Developing ASP components. Sebastopol, CA: O'Reilly \& Associates.

The Campus Computing Project (1999, October). The continuing challenge of instructional integration and user support [Announcement]. Encino, CA: Kenneth C. Green. Retrieved October 21, 1999 at http://www.campuscomputing.net/summaries/1999/index.html

WEISSINGER, A. K. (1999). ASP in a Nutshell: A desktop quick reference. Sebastopol, CA: O’Reilly \& Associates.

White, R. J., \& HAMmer, C. A. (1999). [Use of a Web practice quiz in introductory psychology courses]. Unpublished raw data.

Worthington, E. L., JR., Welsh, J. A., Archer, C. R., Mindes, E. J., \& Forsyth, D. R. (1996). Computer-assisted instruction as a supplement to lectures in an introductory psychology class. Teaching of Psychology, 23, 175-181.

(Manuscript received November 3, 1999; revision accepted for publication February 27, 2000.) 